Frontiers in Heat and Mass Transfer

\title{
HEAT AND MASS TRANSFER ON MHD NANOFLUID FLOW PAST A VERTICAL POROUS PLATE IN A ROTATING SYSTEM
}

\author{
P.V. Satya Narayana ${ }^{\text {a, }}{ }^{*}$, B.Venkateswarlu ${ }^{\text {b }}$ \\ ${ }^{a}$ Fluid Dynamics Division, SAS, VIT University, Vellore - 632 014, T.N, India \\ ${ }^{b}$ Department of Mathematics, Madanapalle Institute of Eng. College, A. Madanapalle, A.P, India
}

\begin{abstract}
In this paper, we study the chemical reaction and heat source effects on unsteady MHD free convection heat and mass transfer of a nanofluid flow past a semi-infinite flat plate in a rotating system. The plate is assumed to oscillate in time with steady frequency so that the solutions of the boundary layer are the similar oscillatory type. The innovation of the present work is closed-form analytic solutions are obtained for the momentum, energy and concentration equations. The influence of various parameters entering into the problem in the nanofluid velocity, temperature and concentration distributions, as well as the skin friction coefficient, Nusselt number and Sherwood number are discussed by considering three different types of nanoparticles with the help of graphs and tables. This model finds applications in studying magnetic resonance imaging, data storage, biomedicine and thermal enhancement of energy systems.

Keywords: Nanofluid, Chemical reaction, Thermal Radiation, Rotating frame, MHD, Porous plate, Heat source
\end{abstract}

\section{INTRODUCTION}

The theory of nanofluid is first introduced by Choi (1995) and has been a field of active research area for about two decades. This fluid is a suspension of a nanometer size solid particles and fibres in a convectional base fluid. Commonly used base fluids for this purpose are water, toluene, oil and ethylene glycol mixture etc. The choice of base fluid-particle combination depends on the application for which the nanofluid is intended. The solid particles used for a nanofluid are metallic solids viz. copper, aluminum, silver and gold; nonmetallic solids viz. Silicon $(\mathrm{SiO})$, alumina $\left(\mathrm{Al}_{2} \mathrm{O}_{3}\right)$ etc. and metallic liquid viz. Sodium. In recent years, the concept of a nanofluid has been proposed as a route for enhancing the performance of the heat transfer rates in the liquids. Materials, with sizes of nanometers possess unique physical and chemical properties. They can flow smoothly through microchannels without clogging because they are sufficiently small to behave similar to liquid molecules Khanafer et al. (2003). This fact has attracted much research into the investigation of the heat transfer characteristics in nanofluids. It has been found that the presence of nanoparticles within the fluid can appreciably increase the effective thermal conductivity of the fluid and, as a consequence, enhance the heat transfer characteristics. An excellent collection of articles on this topic can be found in the book Das et al. (2007) and in the review papers (Xu et al., 2013; Trisaksri and Wongwises, 2009; Kakac and Pramuanjaroenkij, 2009; Soleimani et al., 2012; Fakour, 2014; Nield and Kuznetsov, 2014; Das, 2014; Pourmehran, 2015; Ramesh, 2016).

In the recent years, a great progress in a new generation of MHD heat and mass transfer flow of a nanofluid which provide very desirable features in materials processing, energy applications and also medical engineering. Sheikholeslami et al. (2013, 2014, 2015) have presented the simulation of $\mathrm{MHD} \mathrm{CuO}$ and $\mathrm{Al}_{2} \mathrm{O}_{3}$-water nanofluid flow and convective heat transfer considering Lorentz forces. Turkyilmazoglu (2014) has studied exact analytical solutions for heat and mass transfer of MHD slip flow in nanofluids. Das and Rana (2015) have analyzed the natural convective magneto-nanofluid flow and radiative heat transfer past a moving vertical plate. Satya Narayana et al. (2015) have studied the influence of thermal radiation and heat source on MHD nanofluid past a vertical plate in a rotating system. Ram Reddy et al. (2013) have analyzed the Soret effects on mixed convection flow in a nanofluid by considering convective boundary condition. Very recently, Das et al. (2016) have examined the transient natural convection in a vertical channel filled with nanofluids in the presence of thermal radiation.

The study of heat and mass transfer with chemical reaction in the presence nanofluids is of immense realistic significance to engineers and scientists because of its almost universal incidence in many branches of science and engineering. This phenomenon plays an important role in chemical industry, power and cooling industry for drying, chemical vapor deposition on surfaces, cooling of nuclear reactors and petroleum industries. Venkateswarlu and Satya Narayana (2015) have analysed the chemical reaction and radiation absorption effects on the flow and heat transfer of a nanofluid in a rotating system. Effect of chemical reaction on MHD boundary layer flow and melting heat transfer of Williamson nanofluid in porous medium by Krishnamurthy et al. (2016). Mabood et al. (2016) have studied the MHD stagnation point flow heat and mass transfer of nanofluids in porous medium with radiation, viscous dissipation and chemical reaction. Recently, Mahanthesh et al. (2016) have investigated the heat and mass transfer effects on the mixed convective flow of chemically reacting nanofluid past a moving/stationary vertical plate. Recently, the effect of chemical reaction with heat radiation in presence of nanofluid over a porous vertical stretching surface is investigated by Rosmila Abdul-Kahar et al. (2011) and it is observed that the thermophoresis particle deposition and Brownian diffusion motion have substantial effects on the flow field. Kandasamy et al. (2011) have analyzed the impact of thermophoresis particle deposition and Brownian diffusion motion on nanofluid in the presence of magnetic field and it is predicted that the magnetic strength plays a significant role on the nanoparticles

*Corresponding Author. Email: pvsatya@yahoo.co.in 
in the presence of base fluid. Recently, many researchers Venkateswarlu Satya Narayana (2015); Satya Narayana and Harish Babu (2016); Macha Madhu and Naikoti Kishan (2015); Gireesha et al. (2016) have studied the flow and heat transfer characteristic of Newtonian/non-Newtonian nanofluids over varies geometries.

Motivated by the above reference work and the numerous possible industrial applications of the problem, it is of paramount interest to investigate the effects of chemical reaction and heat source on MHD nanofluid flow in a rotating system with three different types of nanoparticles. It is worth mentioning that the nanofluid model proposed by Buongiorno (2006) is used by many recent studies (Rana and Bharava, 2012; Alsaedi and Hayat, 2012; Hajipour and Molaei Dehkordi, 2012). However, we are following the nanofluid model proposed by Tiwari and Dass (2007), which is being used by many current researches Hamad and Ferdows (2012); Norifiah Bachok (2012); Hamad and Pop (2011) on various flow fields. The layout of the paper as follows. The problem formulation and its solution is presented in Section 2. In Section 3, we present results and discussion. Finally, Section 4 contains the main conclusions.

\section{MATHEMATICAL FORMULATION OF THE PROBLEM}

Let us consider unsteady three dimensional flow of a nanofluid past a semi-infinite vertical permeable plate in a rotating system with chemical reaction, thermal diffusion and the thermal radiation in the presence of a uniform transverse magnetic field. It is assumed that there is no applied voltage which implies the absence of an electric field. The flow is assumed to be in the $\bar{x}$-direction which is taken along the plate in the upward direction, the $\mathrm{Y}$-axis is normal to it and the $\bar{z}$ axis along the width of the plate as shown in Fig. 1. Also it is assumed the whole system is rotate with a constant vector $\Omega$ about $\bar{z}$-axis. The radiation heat flux in $\bar{x}$ direction is considered negligible in comparison that the $\bar{z}$ direction. Due to semi-infinite plate surface assumption the flow variables are functions of $\mathrm{z}$ and time $\mathrm{t}$ only.

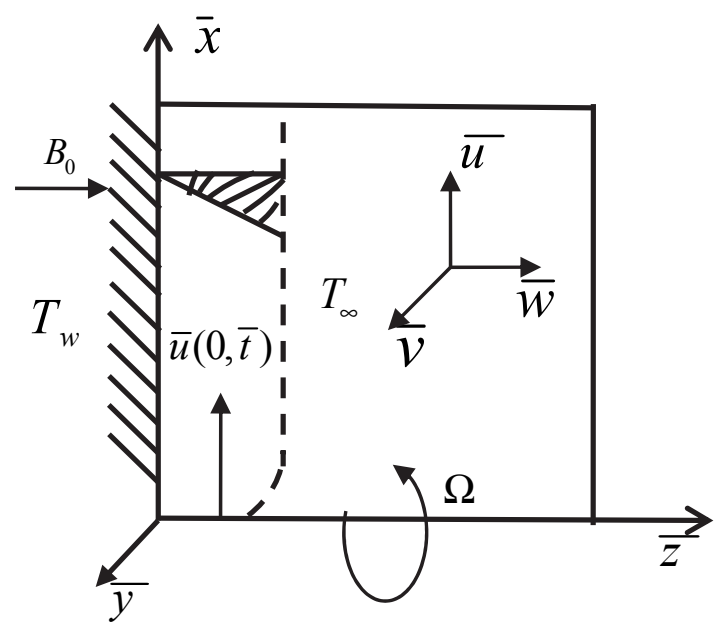

Fig. 1 Physical model and coordinate system of the problem

Under above assumptions, the governing equations of the problem are:

$$
\begin{aligned}
& \frac{\partial \bar{w}}{\partial \bar{z}}=0 \\
& \frac{\partial \bar{u}}{\partial \bar{t}}+\bar{w} \frac{\partial \bar{u}}{\partial \bar{z}}-2 \Omega \bar{v}=\frac{1}{\rho_{n f}}\left\{\mu_{n f} \frac{\partial^{2} \bar{u}}{\partial \bar{z}^{2}}+(\rho \beta)_{n f} g\left(T-T_{\infty}\right)-\frac{v_{f} \bar{u}}{k}-\sigma B_{o}^{2} \bar{u}\right\}
\end{aligned}
$$

$$
\begin{aligned}
& \frac{\partial \bar{v}}{\partial \bar{t}}+\bar{w} \frac{\partial \bar{v}}{\partial \bar{z}}+2 \Omega \bar{u}=\frac{1}{\rho_{n f}}\left\{\mu_{n f} \frac{\partial^{2} \bar{v}}{\partial \bar{z}^{2}}-\frac{v_{f} \bar{u}}{k}-\sigma B_{o}^{2} \bar{v}\right\} \\
& \frac{\partial T}{\partial \bar{t}}+\bar{w} \frac{\partial T}{\partial \bar{z}}=\alpha_{n f} \frac{\partial^{2} T}{\partial \bar{z}^{2}}-\frac{1}{\left(\rho C_{P}\right)_{n f}} \frac{\partial q_{r}}{\partial \bar{z}}-\frac{Q_{H}}{\left(\rho C_{p}\right)_{n f}}\left(T-T_{\infty}\right) \\
& \frac{\partial C}{\partial \bar{t}}+\bar{w} \frac{\partial C}{\partial \bar{z}}=D_{B} \frac{\partial^{2} C}{\partial \bar{z}^{2}}+\frac{D_{T}}{T_{\infty}} \frac{\partial^{2} T}{\partial \bar{z}^{2}}-K_{l}\left(C-C_{\infty}\right)
\end{aligned}
$$

The relavant boundary conditions are

$$
\begin{aligned}
& \bar{u}(\bar{z}, \bar{t})=0 \quad \bar{v}(\bar{z}, \bar{t})=0 \quad T=T_{\infty} \quad C=C_{\infty} \quad \text { for } \bar{t} \leq 0 \text { and any } \bar{z} \\
& \bar{u}(0, \bar{t})=U_{0}\left\{1+\frac{\varepsilon}{2}\left(e^{\text {int }}+e^{- \text {int }}\right)\right\} \quad \bar{v}(0, \bar{t})=0 \quad T(0, \bar{t})=T_{\infty} C(0, \bar{t})=C_{\infty} \\
& \bar{u}(\infty, \bar{t}) \rightarrow 0 \quad \bar{v}(\infty, \bar{t}) \rightarrow 0 \quad T(\infty, \bar{t}) \rightarrow T_{\infty} \quad C(\infty, \bar{t}) \rightarrow C_{\infty} \text { for } \bar{t} \geq 0
\end{aligned}
$$

The properties of nanofluids are defined as follows

$$
\begin{aligned}
& \rho_{n f}=(1-\phi) \rho_{f}+\phi \rho_{s} \\
& \left(\rho C_{p}\right)_{n f}=(1-\phi)\left(\rho C_{p}\right)_{f}+\phi\left(\rho C_{p}\right)_{s} \\
& (\rho \beta)_{n f}=(1-\phi)(\rho \beta)_{f}+\phi(\rho \beta)_{s} \\
& \mu_{n f}=\frac{\mu_{f}}{(1-\phi)^{2.5}} \quad \alpha_{n f}=\frac{K_{n f}}{\left(\rho C_{p}\right)_{n f}} \\
& K_{n f}=K_{f}\left\{\frac{K_{s}+2 K_{f}-2 \phi\left(K_{f}-K_{s}\right)}{K_{s}+2 K_{f}+2 \phi\left(K_{f}-K_{s}\right)}\right\}
\end{aligned}
$$

We consider the solution of equation (1) as:

$\bar{w}=-w_{0}$

The radiative heat term by using the Rosseland approximation is given by

$$
\begin{aligned}
& q_{r}=\frac{-4 \sigma^{*}}{3 k^{*}} \frac{\partial T^{4}}{\partial z} \\
& T^{4}=4 T_{\infty}^{3} T-3 T_{\infty}^{4} \\
& \frac{\partial q_{r}}{\partial \bar{z}}=-16 \frac{T_{\infty}^{3} \sigma^{*}}{3 k^{*}} \frac{\partial^{2} T}{\partial \bar{z}^{2}}
\end{aligned}
$$

We introducing the following non-dimensional quantities:

$$
\begin{aligned}
& u=\frac{\bar{u}}{U_{0}} \quad v=\frac{\bar{v}}{U_{0}} \quad z=\left(\frac{U_{0}}{v_{f}}\right) \bar{z} \quad t=\left(\frac{U_{0}^{2}}{v_{f}}\right) \bar{t} \quad n=\left(v_{f} / U_{0}^{2}\right) \bar{n} \quad F=\frac{4 \sigma^{*} T_{\infty}^{3}}{k k^{*}} \\
& u=\frac{\bar{u}}{U_{0}} \quad v=\frac{\bar{v}}{U_{0}} \quad z=\left(\frac{U_{0}}{v_{f}}\right) \bar{z} \quad t=\left(\frac{U_{0}^{2}}{v_{f}}\right) \bar{t} \quad n=\left(v_{f} / U_{0}^{2}\right) \bar{n} \quad F=\frac{4 \sigma^{*} T_{\infty}^{3}}{k k^{*}} \\
& R=\frac{2 \Omega v_{f}}{U_{0}^{2}} S=\frac{w_{0}}{U_{0}} S c=\frac{v}{D_{B}} S r=\frac{D_{T}\left(T_{w}-T_{\infty}\right)}{\left(C_{w}-C_{\infty}\right) T_{\infty}} \theta=\frac{\left(T-T_{\infty}\right)}{\left(T_{w}-T_{\infty}\right)} \psi=\frac{C-C_{\infty}}{C_{w}-C_{\infty}}
\end{aligned}
$$

Equation (12) into Equations (2)-(5) yields the following dimensionless equations (dropping primes):

$A_{3}\left\{\frac{\partial u}{\partial t}-S \frac{\partial u}{\partial z}-R v\right\}=\frac{1}{A_{1}} \frac{\partial^{2} u}{\partial z^{2}}+A_{4} \theta-\left(M+\frac{1}{K}\right) u$ 


$$
\begin{aligned}
& A_{3}\left\{\frac{\partial v}{\partial t}-S \frac{\partial v}{\partial z}+R u\right\}=\frac{1}{A_{1}} \frac{\partial^{2} v}{\partial z^{2}}-\left(M+\frac{1}{K}\right) v \\
& A_{5}\left\{\frac{\partial \theta}{\partial t}-S \frac{\partial \theta}{\partial z}\right\}=\frac{1}{\operatorname{Pr}}\left\{A_{2} \frac{\partial^{2} \theta}{\partial z^{2}}-Q \theta\right\} \\
& \frac{\partial \psi}{\partial t}-S \frac{\partial \psi}{\partial z}=\frac{1}{S c} \frac{\partial^{2} \psi}{\partial z^{2}}+S r \frac{\partial^{2} \theta}{\partial z^{2}}-K r \psi
\end{aligned}
$$

Where $A_{1}=(1-\phi)^{2.5} \quad A_{2}=\frac{k_{n f}}{k_{f}}+\frac{4 F}{3} \quad A_{3}=1-\phi+\phi\left(\rho_{s} / \rho_{f}\right)$

$$
A_{4}=1-\phi+\phi(\rho \beta)_{s} /(\rho \beta)_{f} \quad A_{5}=1-\phi+\phi(\rho C p)_{s} /(\rho C p)_{f}
$$

The associated boundary condition (6) becomes:

$u(z, t)=0 v(z, t)=0 \quad \theta(z, t)=0 \psi(z, t)=0$ for $t \leq 0$ any $z$

$u(0, t)=1+\frac{\varepsilon}{2}\left(e^{\mathrm{int}}+e^{-\mathrm{int}}\right) v(0, t)=0 \theta(0, t)=1 \psi(0, t)=1$

$u(\infty, t) \rightarrow 0 v(\infty, t) \rightarrow 0 \theta(\infty, t) \rightarrow 0 \psi(\infty, t) \rightarrow 0$ for $t \geq 0$

Using equation (13) the velocity characteristic $U_{0}$ is defined as:

$U_{0}=\left\{g \beta_{f}\left(T_{w}-T_{\infty}\right) v_{f}\right\}^{1 / 3}$

To obtain desired solutions, we now simplify equations (13)-(16) by putting the fluid velocity in the complex form as:

$\chi(z, t)=u(z, t)+i v(z, t)$ and we get

$A_{3}\left\{\frac{\partial \chi}{\partial t}-S \frac{\partial \chi}{\partial z}+i R \chi\right\}=\frac{1}{A_{1}} \frac{\partial^{2} \chi}{\partial z^{2}}+A_{4} \theta-\left(M+\frac{1}{K}\right) \chi$

The associated boundary conditions (17) become:

$$
\begin{aligned}
& \chi(z, t)=0 \theta(z, t)=0 \quad \psi(z, t)=0 \text { for } t \leq 0 \text { any } z \\
& \chi(0, t)=1+\frac{\varepsilon}{2}\left(e^{\mathrm{int}}+e^{-\mathrm{int}}\right) \quad \theta(0, t)=1 \psi(0, t)=1 \\
& \chi(\infty, t) \rightarrow 0 \quad \theta(\infty, t) \rightarrow 0 \psi(\infty, t) \rightarrow 0 \text { for } t \geq 0
\end{aligned}
$$

\section{METHOD OF SOLUTIONS}

To find the analytical solutions of the above system of partial differential equations (13), (14) and (18) under the boundary conditions (19) in the neighborhood of the plate, we assume that (see Ganepathy Ref. (39))

$$
\begin{aligned}
& \chi(z, t)=\chi_{0}(z, t)+\frac{\varepsilon}{2}\left\{e^{\text {int }} \chi_{1}+e^{-\mathrm{int}} \chi_{2}\right\} \\
& \theta(z, t)=\theta_{0}(z, t)+\frac{\varepsilon}{2}\left\{e^{\mathrm{int}} \theta_{1}+e^{-\mathrm{int}} \theta_{2}\right\} \\
& \psi(z, t)=\psi_{0}(z, t)+\frac{\varepsilon}{2}\left\{e^{\mathrm{int}} \psi_{1}+e^{-\mathrm{int}} \psi_{2}\right\}
\end{aligned}
$$

Invoking the above equations (20)-(22) into the equations (13)-(16) and equating the harmonic and non-harmonic terms and neglecting the

higher order terms of $O\left(\varepsilon^{2}\right)$, we obtain the following set of equations:

\section{Zeroth order equations are:}

$$
\begin{aligned}
& \frac{1}{A_{1}} \chi_{0}^{\prime \prime}+A_{3} S \chi_{0}^{\prime}-\left\{A_{3} i R+M+\frac{1}{K}\right\} \chi_{0}+A_{4} \theta_{0}=0 \\
& A_{2} \theta_{0}^{\prime \prime}+A_{5} S \operatorname{Pr} \theta_{0}^{\prime}-Q \theta_{0}=0 \\
& \psi_{0}^{\prime \prime}+S S c \psi_{0}^{\prime}-S c K r \psi_{0}+S c S r \theta_{0}^{\prime \prime}=0
\end{aligned}
$$

First order equations are:

$$
\begin{aligned}
& \frac{1}{A_{1}} \chi_{1}^{\prime \prime}+A_{3} S \chi_{1}^{\prime}-\left\{A_{3} i(R+n)+M+\frac{1}{K}\right\} \chi_{1}+A_{4} \theta_{1}=0 \\
& A_{2} \theta_{1}^{\prime \prime}+A_{5} S \operatorname{Pr} \theta_{1}^{\prime}-\left\{A_{5} i n \operatorname{Pr}+Q\right\} \theta_{1}=0 \\
& \psi_{1}^{\prime \prime}+S S c \psi_{1}^{\prime}-S c(\text { in }+K r) \psi_{1}+S c \operatorname{Sr} \theta_{1}^{\prime \prime}=0
\end{aligned}
$$

Where primes denote differentiation with respect to $\mathrm{z}$ The corresponding boundary conditions can be written as:

$$
\begin{aligned}
& \chi_{0}=1 \theta_{0}=1 \psi_{0}=1 \quad \chi_{1}=1 \theta_{1}=0 \psi_{1}=0 \quad \chi_{2}=1 \theta_{2}=0 \psi_{2}=0 \text { at } z=0 \\
& \chi_{0} \rightarrow 0 \theta_{0} \rightarrow 0 \psi_{0} \rightarrow 0 \chi_{1} \rightarrow 0 \theta_{1} \rightarrow 0 \psi_{1} \rightarrow 0 \chi_{2} \rightarrow 0 \theta_{2} \rightarrow 0 \psi_{2} \rightarrow 0 \text { at } z \rightarrow 0
\end{aligned}
$$

Solving the above equations with the boundary conditions (29) we obtain the expression for velocity, temperature and concentration as:

$$
\begin{aligned}
& \chi(z, t)=B_{3} e^{-m_{1} z}+B_{4} e^{-m_{3} z}+\frac{\varepsilon}{2}\left\{e^{-m_{4} z} e^{\text {int }}+e^{-m_{5} z} e^{- \text {int }}\right\}(30) \\
& \theta(z, t)=e^{-m_{1} z} \\
& \psi(z, t)=B_{1} e^{-m_{1} z}+B_{2} e^{-m_{2} z}
\end{aligned}
$$

where

$$
\begin{aligned}
& B_{1}=\frac{-S c S r m_{1}^{2}}{m_{1}^{2}-S S c m_{1}-S c S r} B_{2}=1-B_{1} B_{4}=1-B_{3} \\
& B_{3}=\frac{-A_{1} A_{4}\left(1+B_{1}\right)}{m_{1}^{2}-S m_{1} A_{1} A_{3}-A_{1}\left\{i R A_{3}+M+1 / K\right\}} \\
& m_{1}=A_{5} S \operatorname{Pr}+\sqrt{\left(S \operatorname{Pr} A_{5}\right)^{2}+\left(4 Q A_{2}\right)} / 2 A_{2} \\
& m_{2}=S S c+\sqrt{(S S c)^{2}+4 S c K r} / 2 \\
& m_{3}=S A_{1} A_{3}+\sqrt{\left(S A_{1} A_{3}\right)^{2}+4 A_{1}\left\{i R A_{3}+M+1 / K\right\}} \backslash 2 \\
& m_{4}=S A_{1} A_{3}+\sqrt{\left(S A_{1} A_{3}\right)^{2}+4 A_{1}\left\{i R A_{3}+M+1 / K\right\}} / 2
\end{aligned}
$$

The physical quantities of engineering interest are skin-friction coefficient, Nusselt number and Sherwood number are, respectively, defined as:

The local skin friction coefficient $C_{f}$ is given by

$C_{f}=\frac{\bar{\tau}_{w}}{\rho_{f} U_{0}^{2}}=-\left(\mathrm{Re}_{x}\right)^{\frac{1}{2}} \frac{1}{(1-\phi)^{2.5}} \chi^{\prime}(0)$ 
The local Nusselt number $N u$ is given by

$N u=\frac{\bar{x} \bar{q}_{w}}{k_{f}\left(T_{w}-T_{\infty}\right)}=-\left(\operatorname{Re}_{x}\right)^{\frac{1}{2}} \frac{k_{n f}}{k_{f}} \theta^{\prime}(0)\left(1+\frac{4 F}{3}\right)$

The local Sherwood number $S h_{x}$ is given by

$S h_{x}=\frac{\bar{x} \bar{q}_{m}}{D_{B}\left(C_{w}-C_{\infty}\right)}=-\left(\operatorname{Re}_{x}\right)^{\frac{1}{2}} \psi^{\prime}(0)$

Where $\bar{\tau}, \bar{q}_{w}$ and $\bar{q}_{m}$ are the wall shear stresses or skin friction, the wall heat flux and the wall mass flux from the plate respectively

\section{RESULT AND DISCUSSION}

In order to get physical insight into the problem, we have carried out numerical calculations for non-dimensional velocity, temperature and species concentration, skin-friction, and Nusselt number by assigning some specific values to the parameters entering into the problem for three different types of water based nanofluids. For this purpose, Figs. 2-8 have been displayed. Table 1 shows the thermo physical properties of water and the Nano elements $\left(\mathrm{Cu}, \mathrm{Al}_{2} \mathrm{O}_{3}\right.$ and $\left.\mathrm{TiO}_{2}\right)$. To verify the validity and exactness of the present results, we have compared skin friction co efficient and local Nusselt number with those of Satya Narayana et al. [18] and Hamad et al. [38] for various values of Pr. The results of this comparison are given in Table 2 and found them to be in excellent agreement. Therefore, we are confident that the present results are more accurate.

Table 1: Thermo-physical properties

\begin{tabular}{|l|l|l|l|l|}
\hline $\begin{array}{l}\text { Physical } \\
\text { Properties }\end{array}$ & Water & $\begin{array}{l}\text { Copper } \\
(\mathrm{Cu})\end{array}$ & $\begin{array}{l}\text { Aluminium } \\
\text { Oxide }\left(\mathrm{Al}_{2} \mathrm{O}_{2}\right)\end{array}$ & $\begin{array}{l}\text { Titanium } \\
\text { Oxide }\left(\mathrm{TiO}_{2}\right)\end{array}$ \\
\hline $\mathrm{Cp}$ & 4179 & 385 & 765 & 686.2 \\
\hline$\rho$ & 997.1 & 8933 & 3970 & 4250 \\
\hline $\mathrm{K}$ & 0.613 & 400 & 40 & 8.9538 \\
\hline$\beta \times 10^{-5}$ & 21 & 1.67 & 0.85 & 0.9 \\
\hline
\end{tabular}

Table 2: Comparison of skin-friction and Nusselt number of the present case with those of Hamad and Pop (2011) and Satya Narayana et al. (2015) for $\mathrm{S}=1.0 ; \mathcal{E}=0.02 ; \mathrm{R}=0.02 \mathrm{n}=10.0 ; \mathrm{t}=0.1 ; \mathrm{M}=0.5, \mathrm{~F}=1.0$; $\mathrm{Q}=10.0 \phi=0.15 ; \mathrm{K}=0.05$.

\begin{tabular}{|c|c|c|c|}
\hline \multirow{2}{*}{ Pr } & \multicolumn{3}{|c|}{ Skin Friction } \\
\cline { 2 - 4 } & $\begin{array}{c}\text { Hamad and } \\
\text { Pop (2011) }\end{array}$ & $\begin{array}{c}\text { Satya Narayana } \\
\text { et al. }(2015)\end{array}$ & $\begin{array}{c}\text { Present } \\
\text { Study }\end{array}$ \\
\hline 0.5 & 2.3202 & 2.3159708 & 2.3159708 \\
1.0 & 2.2586 & 2.2567503 & 2.2567503 \\
1.5 & 2.1967 & 2.1972895 & 2.1972895 \\
2.0 & 2.1345 & 2.1376083 & 2.1376083 \\
\hline & \multicolumn{3}{|c|}{ Nusselt number } \\
\hline & Hamad and & Satya Narayana & Present \\
Pr & Pop (2011) & et al. (2015) & Study \\
\hline 0.5 & 5.9674 & 5.9674231 & 5.9674231 \\
1.0 & 6.0461 & 6.0461932 & 6.0461932 \\
1.5 & 6.1259 & 6.1259433 & 6.1259433 \\
2.0 & 6.2066 & 6.2066709 & 6.2066709 \\
\hline
\end{tabular}

Table 3: Values of skin friction and Sherwood number for various values of $\phi$ and $\mathrm{M}$

\begin{tabular}{|c|c|c|c|c|}
\hline \multirow[t]{2}{*}{$\mathrm{M}$} & \multirow[t]{2}{*}{$\phi$} & \multicolumn{3}{|c|}{$\begin{array}{c}\text { Skin Friction } \\
\mathcal{E}=0.01 ; \mathrm{n}=10.0 ; t=\pi / 2 \mathrm{~F}=1.0 ; \operatorname{Pr}=6.2 ; \mathrm{Q}=10.0 \\
\mathrm{~K}=0.05 ; \mathrm{R}=0.02, \mathrm{~S}=1.0\end{array}$} \\
\hline & & $\mathrm{Cu}$ & $\mathrm{TiO}_{2}$ & $\mathrm{Al}_{2} \mathrm{O}_{3}$ \\
\hline \multirow{4}{*}{0.0} & 0.1 & 0.602340 & 0.466184 & 0.382986 \\
\hline & 0.2 & 0.395930 & 0.315610 & 0.270562 \\
\hline & 0.3 & 0.175041 & 0.158834 & 0.135920 \\
\hline & 0.4 & 0.028650 & 0.025187 & 0.024582 \\
\hline \multirow{4}{*}{0.5} & 0.1 & 0.602547 & 0.473703 & 0.383277 \\
\hline & 0.2 & 0.396003 & 0.319424 & 0.270715 \\
\hline & 0.3 & 0.175100 & 0.162048 & 0.135992 \\
\hline & 0.4 & 0.028734 & 0.025256 & 0.024630 \\
\hline \multirow{4}{*}{1.0} & 0.1 & 0.602758 & 0.481499 & 0.383573 \\
\hline & 0.2 & 0.396079 & 0.323406 & 0.270871 \\
\hline & 0.3 & 0.175161 & 0.166150 & 0.136066 \\
\hline & 0.4 & 0.028820 & 0.025313 & 0.024680 \\
\hline \multirow{4}{*}{$\mathrm{M}$} & \multirow{4}{*}{$\phi$} & & erwood nun & \\
\hline & & $\mathcal{E}=0.01, \mathrm{n}=$ & $=\pi / 2, \mathrm{~F}$ & $\mathrm{r}=6.2, \mathrm{Kr}=1$ \\
\hline & & $\mathrm{Q}=10, \mathrm{~K}=\mathrm{c}$ & $=0.02, S=1$ & $.0, \mathrm{Sr}=1.0$ \\
\hline & & $\mathrm{Cu}$ & $\mathrm{TiO}_{2}$ & $\mathrm{Al}_{2} \mathrm{O}_{3}$ \\
\hline \multirow{4}{*}{0.0} & 0.1 & 1.616428 & 1.456073 & 1.616453 \\
\hline & 0.2 & 1.616441 & 1.465321 & 1.616474 \\
\hline & 0.3 & 1.616455 & 1.474298 & 1.616495 \\
\hline & 0.4 & 1.616469 & 1.482995 & 1.616516 \\
\hline \multirow{4}{*}{0.5} & 0.1 & 1.6164281 & 1.456073 & 1.616453 \\
\hline & 0.2 & 1.616441 & 1.465321 & 1.616474 \\
\hline & 0.3 & 1.616455 & 1.474298 & 1.616495 \\
\hline & 0.4 & 1.616469 & .482995 & 1.616516 \\
\hline \multirow{4}{*}{1.0} & 0.1 & 1.6164281 & 1.456073 & 1.616453 \\
\hline & 0.2 & 1.616441 & 1.465321 & 1.616474 \\
\hline & 0.3 & 1.616455 & 1.474298 & 1.616495 \\
\hline & 0.4 & 1.616469 & 1.482995 & 1.616516 \\
\hline
\end{tabular}

Figs. 2-4 represent the influence of radiation parameter $F$ on the nanofluid velocity, temperature and concentration profiles. It is observed that the nanofluid velocity, temperature and concentration distributions enhance with the increase in radiation parameter $(\mathrm{F})$.

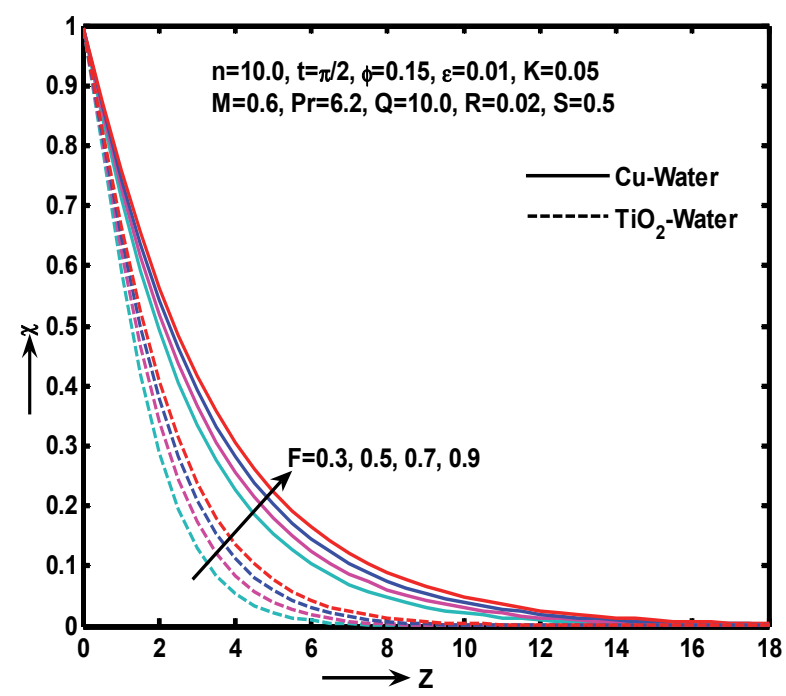

Fig. 2 Velocity profile for various values of $F$ 


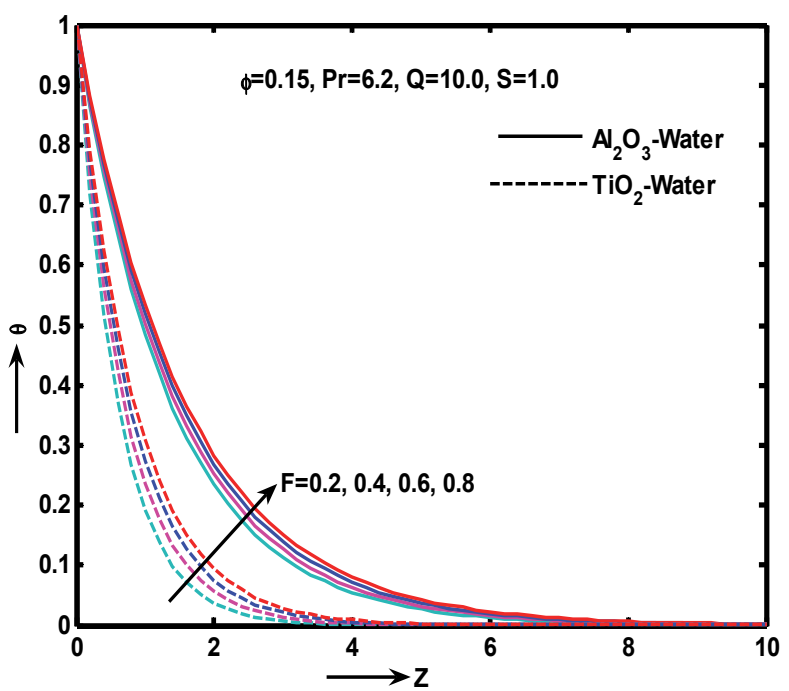

Fig. 3 Temperature profile for various values of $\mathrm{F}$

This is because, the thermal boundary layer thickness increases with an increase in the thermal radiation. Thus, it is pointed out that, the radiation should be minimized to have the cooling process at a faster rate. It is also observed that the nanofluid velocity and temperature in the case of $\mathrm{TiO}_{2}$-water nanofluid is relatively lesser than that of the $\mathrm{Cu}$-water, $\mathrm{Al}_{2} \mathrm{O}_{3}$-water nanofluids. This occurrence has a higher conformity with the physical realities.

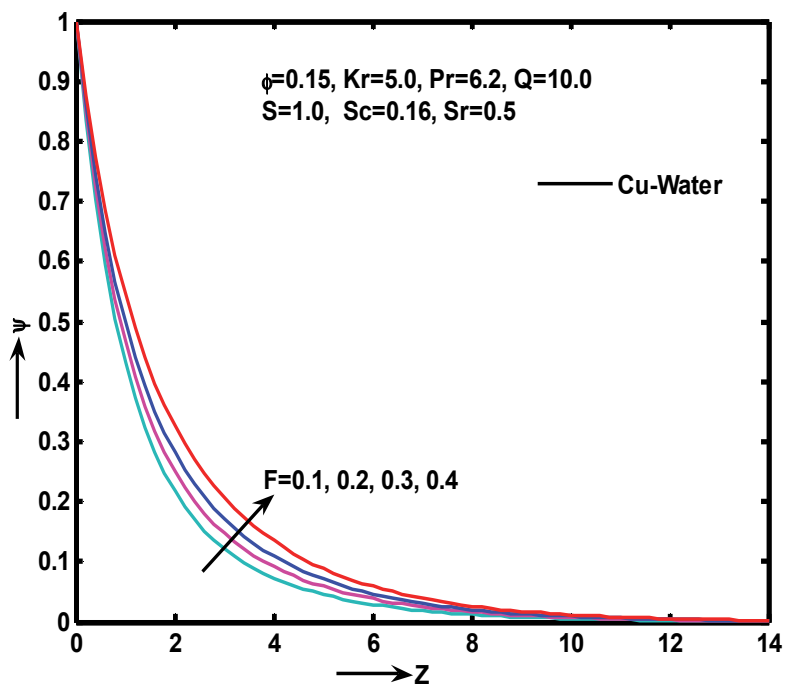

Fig. 4 Concentration profile for various values of $\mathrm{F}$

Fig. 5 shows the influence of magnetic field parameter $M$ on the nanofluid velocity profiles in the boundary layer. Application of magnetic field to an electrically conducting fluid gives rise to a resistive type force called the Lorentz force. This force has the tendency to slow down the motion of the fluid in the boundary layer. Thus the presence of the magnetic field parameter decreases the momentum boundary layers thickness. These results are in good agreement with the results obtained in case of Hamad et al. [38]. Table 3 shows that the skin friction coefficient increases with the increase in $M$ where as $M$ have no effect on Sherwood number.

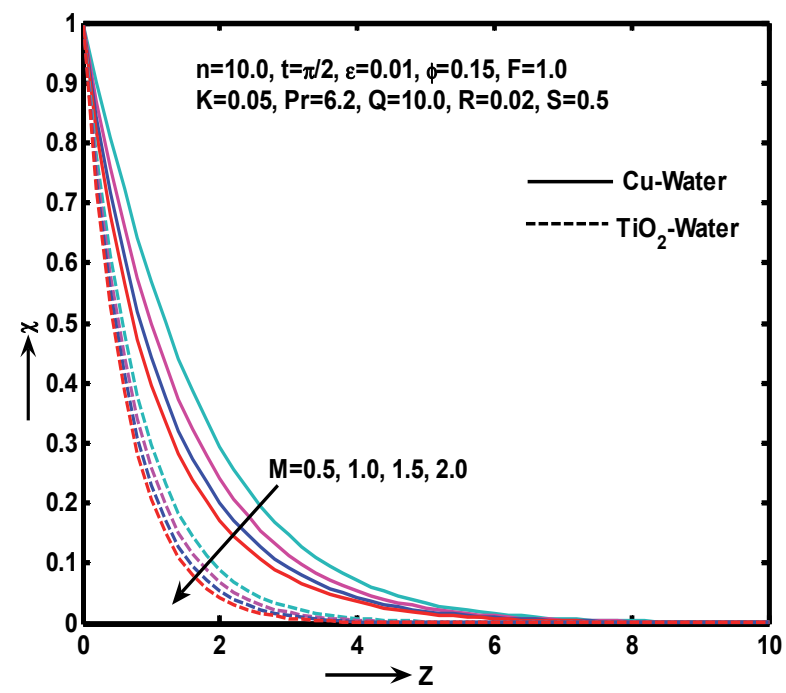

Fig. 5 Velocity profile for various values of $\mathrm{M}$

Also from Eq. (5) it is clear that the equation is independent of $M$. So $M$ has no effect on Sherwood number. This table also displays that the skin friction coefficient and Sherwood number have greater value for $\mathrm{Cu}$ than $\mathrm{Al}_{2} \mathrm{O}_{3}$ and $\mathrm{TiO}_{2}$. This is due to the physical properties of fluid and the thermal conductivity of $\mathrm{Cu}$ is much higher than that of $\mathrm{Al}_{2} \mathrm{O}_{3}$ and $\mathrm{TiO}_{2}$. This means that the nanofluids will be important in the cooling and heating processes.

Figs. 6-8 have been plotted to find the variation of nanofluid velocity, temperature and concentration profiles for different values of heat generation parameter Q. It is clear that, there is a decrease in the velocity and temperature with increase of $\mathrm{Q}$. This is due to the fact that when heat is absorbed, the buoyancy forces decrease which retard the flow rate and thereby give rise to a decrease in the velocity and temperature profiles while the opposite is true in case of concentration profiles.

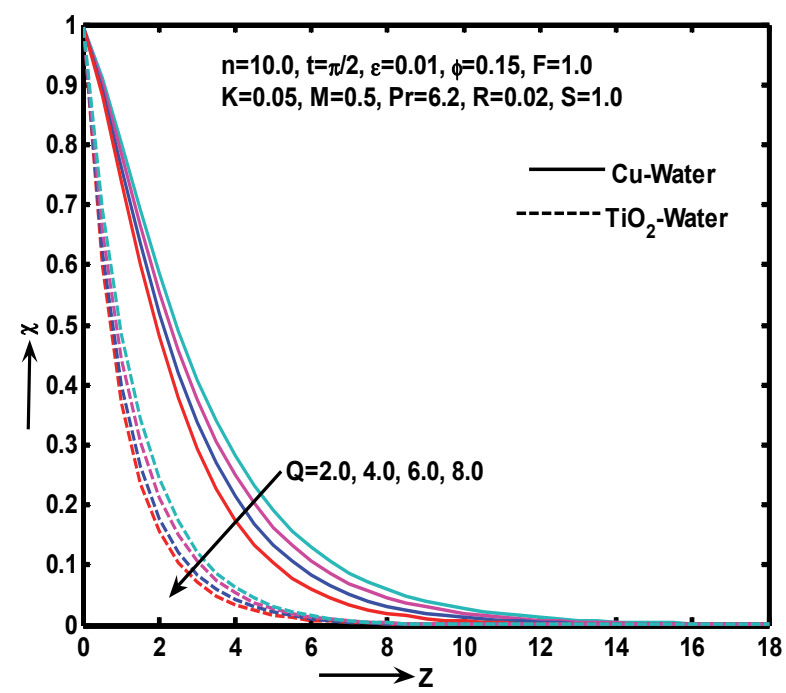

Fig. 6 Velocity profile for various values of $Q$ 


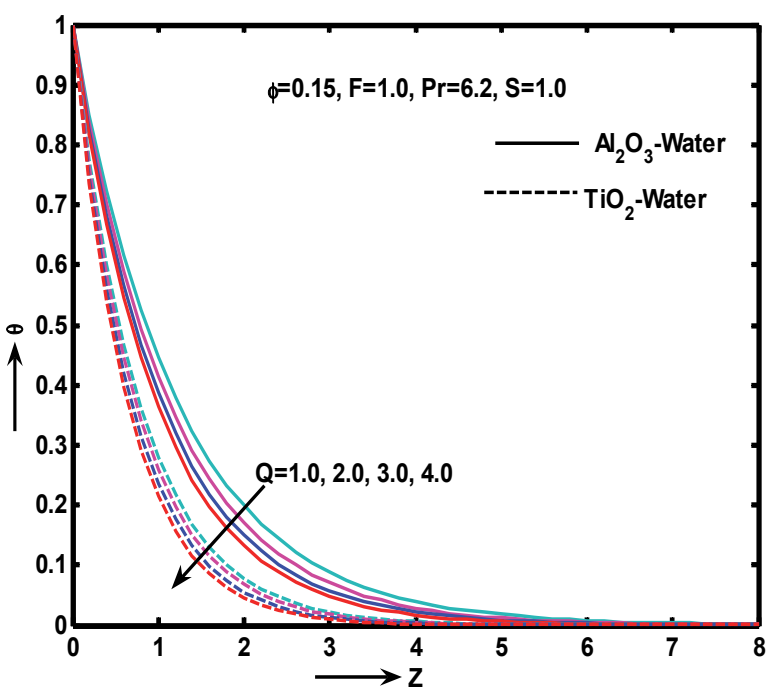

Fig. 7 Temperature profile for various values of $Q$

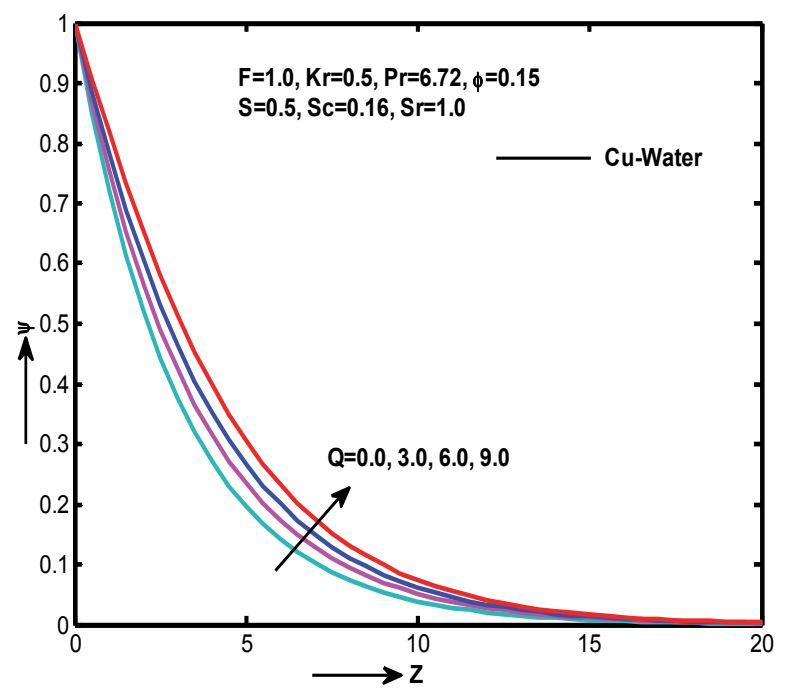

Fig. 8 Concentration profile for various values of $Q$

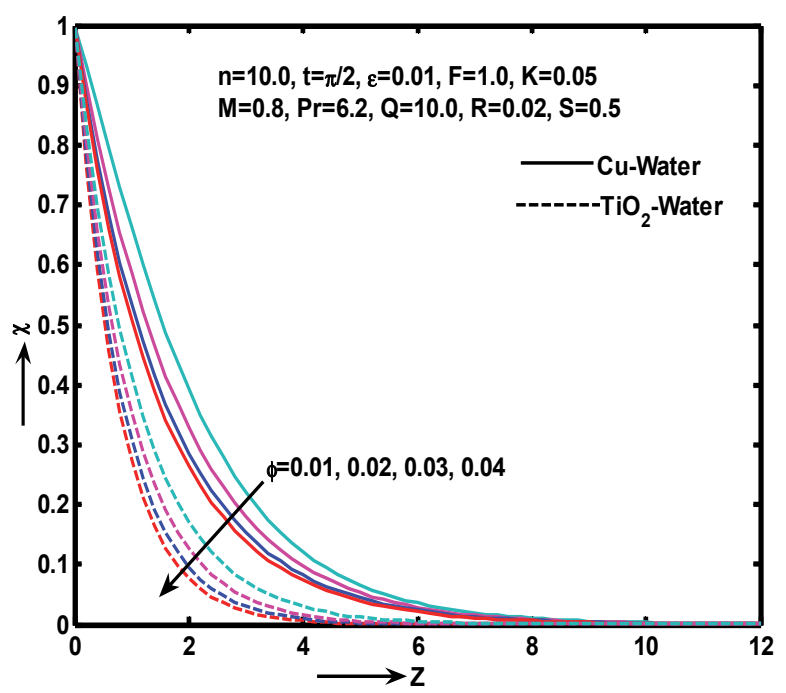

Fig. 9 Velocity profile for various values of $\phi$
Figs. 9-11 display the effect of volume fraction of the nanoparticles on the nanofluid velocity, temperature and concentration profiles, respectively. It is noticed that the velocity decreases with increase of $\phi$ whereas reverse trend is observed in case of temperature and concentration profiles. It is also observed that, with increase of $\phi$, the thermal boundary-layer increases. This agrees with the physical behavior that, when the volume fraction of copper increases, the thermal conductivity increases, and then the thermal boundary-layer thickness increases.

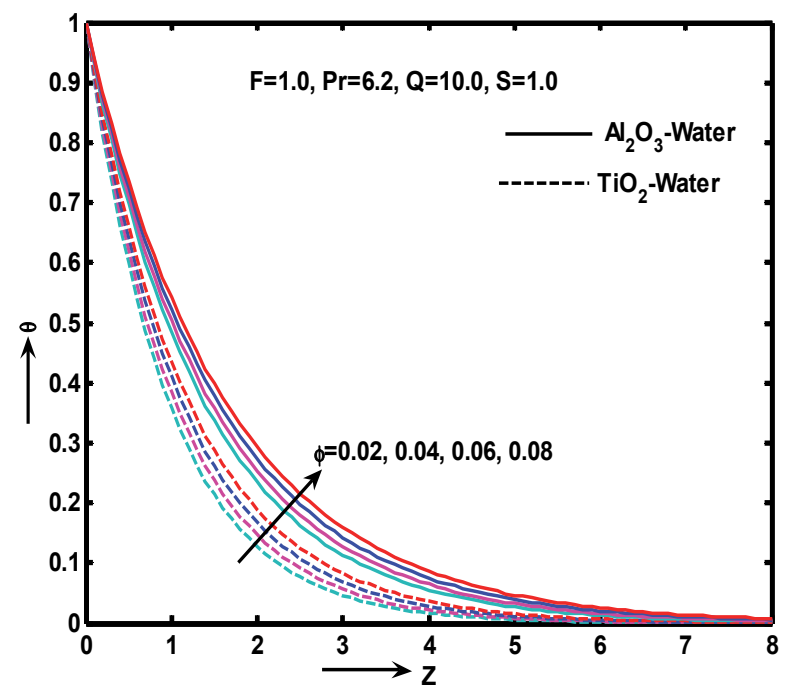

Fig. 10 Temperature profile for various values of $\phi$

We also observe that the nanofluid velocity in the case of $\mathrm{Cu}$-water nanofluid is relatively higher than that of a $\mathrm{TiO}_{2}$ - water nanofluid. In the same vein we also note that the conductivity of $\mathrm{Al}_{2} \mathrm{O}_{3}$ is more than that of $\mathrm{TiO}_{2}$ and the temperature distribution in the $\mathrm{Al}_{2} \mathrm{O}_{3}$-water nanofluid is higher than that of the $\mathrm{TiO}_{2}$-water nanofluid.

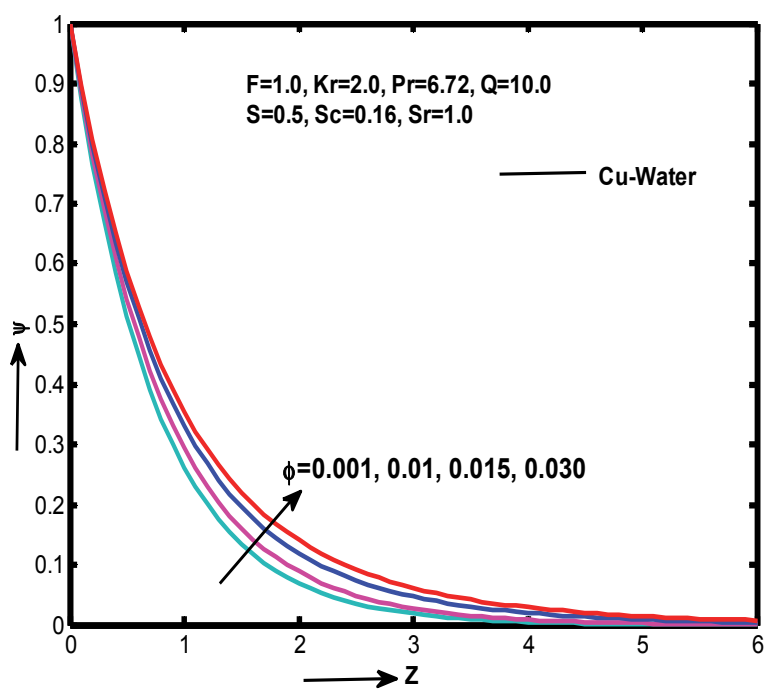

Fig. 11 Concentration profile for various values of $\phi$

It is observed from Fig. 12, the concentration asymptotically decreases from the maximum value 1 to 0 as $z \rightarrow \infty$. This shows that the concentration field is greatest near the plate surface and least in the outer flow region. The same figure further indicates that there is a 
steady fall in species concentration due to the effect of chemical reaction. This means that the consumption of chemical species leads to fall in the species concentration field. This clearly agrees with the physical laws.

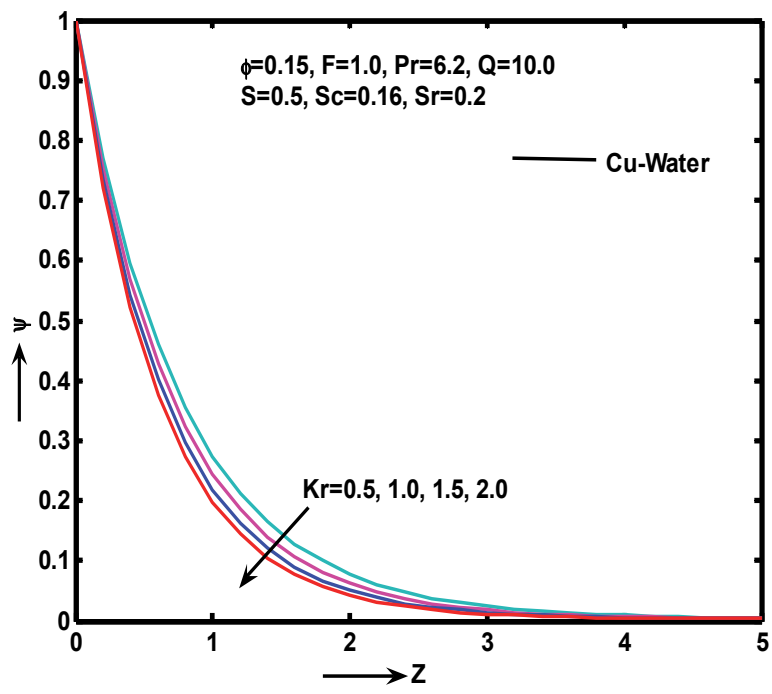

Fig. 12 Concentration profile for various values of $\mathrm{Kr}$

The influence of Soret effect on the concentration profiles is illustrated in figure 13. It is observed that, the increase in $\mathrm{Sr}$ contributes to decrease in the concentration.

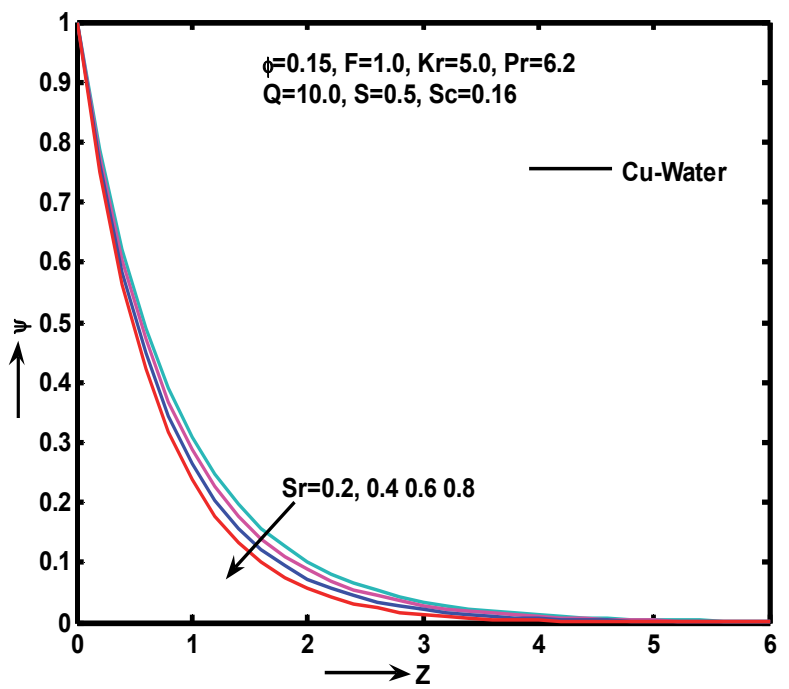

Fig. 13 Concentration profile for various values of $\mathrm{Sr}$

Figure 14 shows the variation of skin friction coefficient $C_{f}$ with respect to suction parameter $\mathrm{S}$ and rotational parameter $\mathrm{R}$. The magnitude of a skin friction coefficient decrease with increasing R. It is also observed that the $\mathrm{Al}_{2} \mathrm{O}_{3}$-water nanofluid has a low skin friction coefficient than $\mathrm{Cu}, \mathrm{TiO}_{2}$-water nanofluids.

The coefficient of Nusselt number is plotted against $\mathrm{F}$ for different values of $Q$ in figure 15. It is obvious that the Nusselt number increases with Q. It is also observed that $C u$-water nanofluid has the highest Nusselt number.

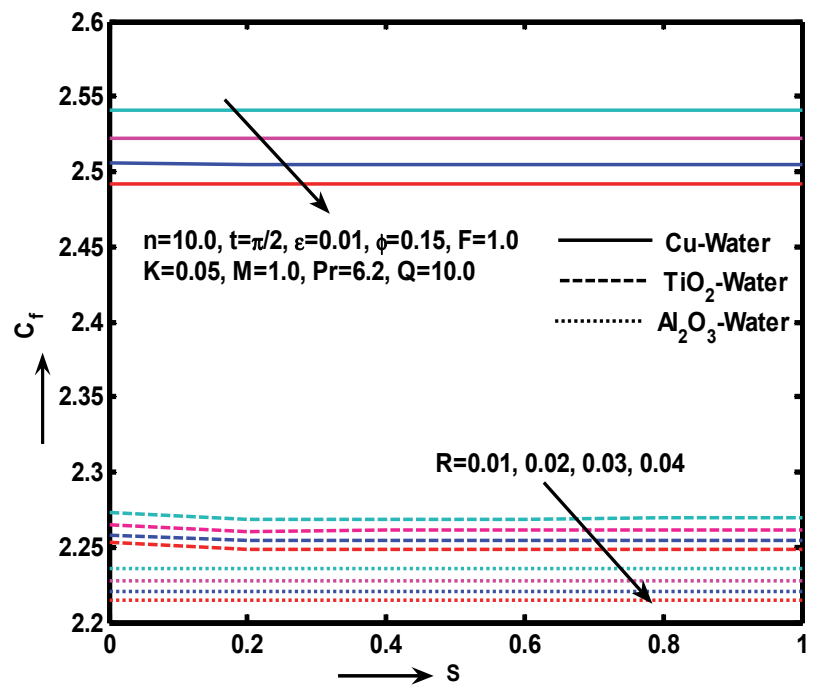

Fig. 14 Skin friction for various values of $\mathrm{R}$

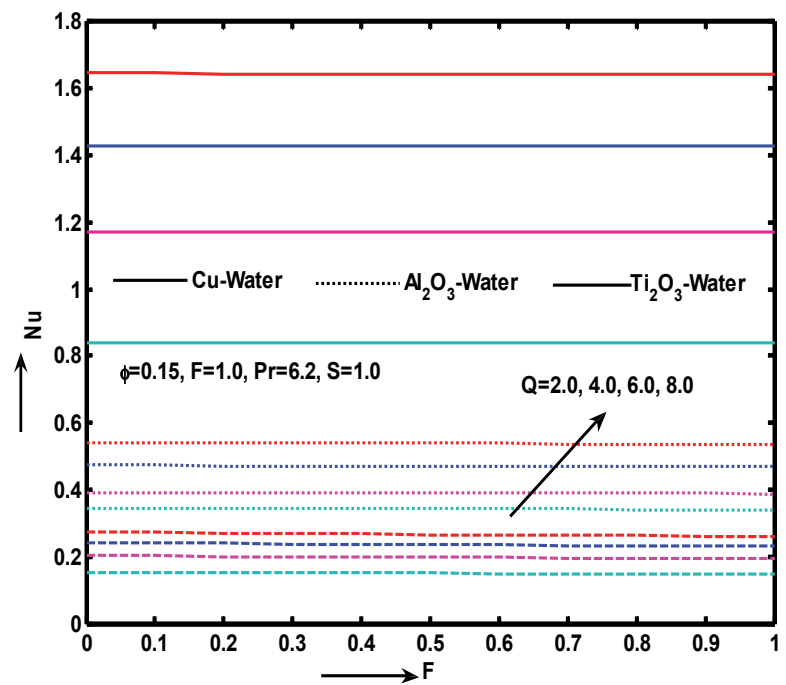

Fig. 15 Nusselt number for various values of Q

\section{CONCLUSIONS}

The following conclusions can be made from the present investigation:

$>$ The copper nanoparticles proved to have the maximum cooling recital for this vertical porous plate problem where Alumina nanoparticles have the lowest. This is due to the high thermal conductivity of $C u$ and low thermal conductivity of $\mathrm{Al}_{2} \mathrm{O}_{3}, \mathrm{TiO}_{2}$

$>$ The velocity profile decreases with an increase in nanoparticle volume fraction parameter, while the opposite is true in the case of temperature and concentration profiles.

$>$ Due to chemical reaction, the concentration of the fluid decreases. This is because the consumption of chemical species leads to a fall in the species concentration field. But it is reverse in case of micropolar fluid [see Ref.40]. This remarkable feature of the concentration profiles in our investigation is due to the presence of Soret number and nanoparticles in the flow field.

$>$ It has been shown that mixing nanoparticles in a liquid (nanofluid) has a dramatic effect on the liquid thermophysical properties such as thermal conductivity. 
We hope that the findings of this investigation may be useful in catalysis, biomedicine, magnetic resonance imaging, data storage and environmental remediation. Hence, the subject of nanofluids is of great interest worldwide for basic and applied research.

\section{NOMENCLATURE}

$B_{0} \quad$ constant applied magnetic field

$C_{f} \quad$ skin friction coefficient

$C_{p} \quad$ specific heat at constant pressure

$C_{\infty} \quad$ concentration of the solute far away from the plate

$D_{m} \quad$ molecular diffusivity

E applied electric field

$F \quad$ heat radiation parameter

$g \quad$ acceleration due to gravity

$G_{r} \quad$ Grashof number

$G_{m} \quad$ modified Grashof number

$K \quad$ permeability parameter

$k \quad$ permeability of porous medium

$k^{*} \quad$ mean absorption coefficient

$M \quad$ dimensionless magnetic field parameter

$\mathrm{Nu} \quad$ Nusselt number

Pr Prandtl number

$Q \quad$ dimensional heat source parameter

$Q_{l} \quad$ dimensional heat generation parameter

$q_{r} \quad$ radiative heat flux

$q_{w} \quad$ heat flux from the plate

$R \quad$ dimensional rotational parameter

$R_{r} \quad$ chemical reaction rate constant

$\mathrm{Re}_{x} \quad$ local Reynolds number

$S \quad$ suction parameter

$S_{c} \quad$ Schmidt number

$\mathrm{Sr} \quad$ soret number

$S h_{x} \quad$ Sherwood number

$w \quad$ condition at the wall

$T \quad$ local Temperature of the nanofluid

$T_{w} \quad$ wall temperature of the fluid

$T_{\infty} \quad$ temperature of the ambient nanofluid

$U_{0} \quad$ characteristic velocity

$(u, v, w) \quad$ velocity components along $\mathrm{x}$ and $\mathrm{y}$ axes

$(x, y, z) \quad$ Cartesian coordinate's

$w_{0} \quad$ normal velocity

\section{GREEK SYMBOLS}

$\alpha \quad$ thermal diffusivity

$\alpha_{f} \quad$ thermal diffusivity of the fluid

$\alpha_{n f} \quad$ thermal diffusivity of the nanofluid

$\beta \quad$ thermal expansion coefficient

$\beta_{f} \quad$ coefficient of thermal expansion of the fluid

$\beta_{S} \quad$ coefficient of thermal expansion of the solid

$\left(\rho_{*} C_{P}\right)_{n f}$ heat capacitance of the nanofluid

$\sigma^{*} \quad$ Stefan-Boltzmann constant parameter

$\sigma \quad$ electrical conductivity of the fluid

$\rho_{f} \quad$ density of the fluid friction

$\rho_{n f} \quad$ density of the nanofluid

$\rho_{S} \quad$ density of the solid friction

$v_{f} \quad$ kinematic viscosity of the fluid $v \quad$ kinematic viscosity

$\mu_{n f} \quad$ viscosity of the nanofluid

$\mu$ dynamic viscosity

$\varepsilon \quad$ small constant quantity

$\chi \quad$ complex function

$\theta \quad$ Non-dimensional Temperature

$\psi \quad$ Non-dimensional Concentration

\section{SUBSCRIPT}

$f \quad$ fluid

$s \quad$ solid

nf nanofluid

$\infty \quad$ condition at free stream

\section{REFERENCES}

Alsaedi, M. Awais and T. Hayat, 2012, "Effect of Heat Generation/Absorption on Stagnation Point Flow of Nanofluid over a Surface with Convective Boundary Conditions," Communications in Nonlinear Science and Numerical Simulation, 17, 4210-4223.

http://dx.doi.org/10.1016/j.cnsns.2012.03.008

Bakr, A.A., 2011, "Effects of Chemical Reaction on MHD Free Convection and Mass Transfer Flow of a Micropolar Fluid with Oscillatory Plate Velocity and Constant Heat Source in a Rotating Frame of Reference," Communications in Nonlinear Science and Numerical Simulation, 16, 698-710.

http://dx.doi.org/10.1016/j.cnsns.2010.04.040

Buongiorno, J., 2006, "Convective Transport in Nanofluids," ASME Journal of Heat Transfer, 128, 240-250.

http://dx.doi.org/10.1115/1.2150834

Choi, S.U.S., 1995, "Enhancing Thermal Conductivity of Fluids with Nanoparticles," In: Proceedings of the ASME International Mechanical Engineering Congress and Exposition, San Francisco, USA. ASME, FED 231/MD, 66, 99-105.

Das, D., 2014, "Flow and Heat Transfer Characteristics of Nanofluids in a Rotating Frame," Alexandria Engineering Journal, 53(3), 757-766 http://dx.doi.org/10.1016/j.aej.2014.04.003

Das, S., and Jana, R.N., 2015, "Natural Convective Magneto-Nanofluid Flow and Radiative Heat Transfer Past a Moving Vertical Plate," Alexandria Engineering Journal, 54, 55-64 http://dx.doi.org/10.1016/j.aej.2015.01.001

Das, S., Jana, R.N., and Makinde, O.D., 2016, "Transient Natural Convection in a Vertical Channel Filled with Nanofluids in the Presence of Thermal Radiation," Alexandria Engineering Journal, 55, 253-262

http://dx.doi.org/10.1016/j.aej.2015.10.013

Das, S.K., Choi, S.U.S., Yu, W., and Pradeep, T., 2007, Nanofluids: Science and Technology, Wiley, Hoboken.

Fakour, M., Vahabzadeh, A., and Ganji, D.D., 2014, "Scrutiny of Mixed Convection Flow of a Nanofluid in a Vertical Channel, Case Study," Thermal Engineering, 4, 15-23. http://dx.doi.org/10.1016/j.csite.2014.05.003

Ganapathy, R., 1994, "A Note on Oscillatory Couette Flow in a Rotating System," ASME Journal of Applied Mechanics, 61, 208-209. http://dx.doi.org/10.1115/1.2901403 
Gireesha, B.J., Mahanthesh, B., Shivakumara, I.S., and Eshwarappa, K.M., 2016, "Melting Heat Transfer in Boundary Layer StagnationPoint Flow of Nanofluid Toward a Stretching Sheet with Induced Magnetic Field," Engineering Science and Technology, 19(1), 313321

http://dx.doi.org/10.1016/j.jestch.2015.07.012

Hamad, M.A.A., and Ferdows, M., 2012, "Similarity Solutions to Viscous Flow and Heat Transfer of Nanofluid over Non-Linearly Stretching Sheet," Applied Mathematics and Mechanics English Edition, 33(7), 923-930.

http://dx.doi.org/10.1007/s10483-012-1595-7

Hamad, M.A.A., and Pop, I., 2011, "Unsteady MHD Free Convection Flow Past a Vertical Permeable Flat Plate in a Rotating Frame of Reference with Constant Heat Source in a Nanofluid," Heat Mass Transfer, 47, 1517-1524.

http://dx.doi.org/10.1007/s00231-011-0816-6

Kakaç, S., and Pramuanjaroenkij, A., 2009, "Review of Convective Heat Transfer Enhancement with Nanofluids," International Journal of Heat and Mass Transfer, 52, 3187-3196.

http://dx.doi.org/10.1016/j.ijheatmasstransfer.2009.02.006

Kandasamy, K., Loganathan, P., and Puvi Arasu, P., 2011, "Scaling Group Transformation for MHD Boundary-Layer Flow of a Nanofluid Past a Vertical Stretching Surface in the Presence of Suction/Injection," Nuclear Engineering and Design, 241, 2053-2059.

http://dx.doi.org/10.1016/j.nucengdes.2011.04.011

Khanafer, K., Vafai, K., and Lightstone, M., 2003, "Buoyancy-Driven Heat Transfer Enhancement in a Two-Dimensional Enclosure Utilizing Nanofluids," International Journal of Heat and Mass Transfer. 46, 3639-3653.

http://dx.doi.org/10.1016/S0017-9310(03)00156-X

Krishnamurthy, M.R., Prasannakumara, B.C., Gireesha, B.J., and Rama Subba Reddy Gorla, 2016, "Effect of Chemical Reaction on MHD Boundary Layer Flow and Melting Heat Transfer of Williamson Nanofluid in Porous Medium," Engineering Science and Technology, 19(1) , 53-61

http://dx.doi.org/10.1016/i.jestch.2015.06.010

Mabood, F., Shateyi, S., Rashidi, M.M., Momoniat, E., and Freidoonimehr, N., 2016, "MHD Stagnation Point Flow Heat and Mass Transfer of Nanofluids in Porous Medium with Radiation, Viscous Dissipation and Chemical Reaction," Advanced Powder Technology, 27(2), 742-74.

http://dx.doi.org/10.1016/j.apt.2016.02.033

Macha Madhu, and Naikoti Kishan, 2015, "Finite Element Analysis of Heat and Mass Transfer by MHD Mixed Convection Stagnation-point Flow of a Non-newtonian Power-law Nanofluid towards a Stretching Surface with Radiation," Journal of the Egyptian Mathematical Society. http://dx.doi.org/10.1016/j.joems.2015.06.001

Mahanthesh, B., Gireesha, B.J., and Rama Subba Reddy Gorla, 2016, "Heat and Mass Transfer Effects on the Mixed Convective Flow of Chemically Reacting Nanofluid Past A Moving/stationary Vertical Plate," Alexandria Engineering Journal.

http://dx.doi.org/10.1016/j.aej.2016.01.022

Mastaneh Hajipour and Asghar Molaei Dehkordi, 2012, "Analysis of Nanofluid Heat Transfer In Parallel-plate Vertical Channels Partially Filled with Porous Medium," International Journal of Thermal Science, $\mathbf{5 5}, 103-113$

http://dx.doi.org/10.1016/j.ijthermalsci.2011.12.018
Nield, D.A., and Kuznetsov, A.V., 2014, "Forced Convection in a Parallel -plate Channel Occupied by a Nanofluid or a Porous Medium Saturated by a Nanofluid," International Journal of Heat and Mass Transfer, 70, 430-433.

http://dx.doi.org/10.1016/j.ijheatmasstransfer.2014.04.051

Norifiah Bachok, Anuar Ishak and Ioan Pop, 2012, "Boundary Layer Flow Over A Moving Surface in A Nanofluid with Suction or Injection," Acta Mech Sin., 28(1), 34-40.

http://dx.doi.org/10.1007/s10409-012-0014-x

Pourmehran, O., Rahimi-Gorji, M., Gorji-Bandpy, M., and Ganji, D.D., 2015, "Analytical Investigation of Squeezing Unsteady Nanofluid Flow between Parallel Plates by LSM and CM," Alexandria Engineering Journal, 54 (1), 17-26

http://dx.doi.org/10.1016/j.aej.2014.11.002

Ramesh, G.K., Gireesha, B.J., Hayat, T., Alsaedi, A., 2016, "Stagnation Point Flow of Maxwell Fluid towards a Permeable Surface in the Presence of Nanoparticles," Alexandria Engineering Journal.

http://dx.doi.org/10.1016/j.aej.2016.02.007

RamReddy, Ch., Murthy, P.V.S.N., Chamkha, Ali J., and Rashad, A.M., 2013, "Soret Effect On Mixed Convection Flow in a Nanofluid under Convective Boundary Condition," International Journal of Heat and Mass Transfer, 64, 384-392.

http://dx.doi.org/10.1016/j.ijheatmasstransfer.2013.04.032

Rana, and Bharava, R., 2012, "Flow and Heat Transfer of a Nanofluid over a Nonlinearly Stretching Sheet," Communications in Nonlinear Simulation, 7, 212-226.

http://dx.doi.org/10.1016/i.cnsns.2011.05.009

Rosmila Abdul-Kahar, Kandasamy, R., and Muhaimin, 2011, "Scaling Group Transformation for Boundary-Layer Flow of a Nanofluid Past a Porous Vertical Stretching Surface in the Presence of Chemical Reaction with Heat Radiation," Computers and Fluids, 52, 15-21. http://dx.doi.org/10.1016/j.compfluid.2011.08.003

Satya Narayana, P.V., and Harish Babu, D., 2016, "Numerical MHD Heat and Mass Transfer Jeffrey Fluid over a Stretching Sheet with Chemical Reaction and Radiation Parameter," Journal of the Taiwan Institute of Chemical Engineers, 59, 18-25.

http://dx.doi.org/10.1016/j.jtice.2015.07.014

Satya Narayana, P.V., Venkateswarlu, B., and Venkataramana, S., 2015, "Thermal Radiation and Heat Source Effects on MHD Nanofluid Past a Vertical Plate in a Rotating System with Porous Medium. Heat Transfer-Asian Research, 44 (1), 1-19

http://dx.doi.org/10.1002/htj.21101

Sheikholeslami, M., Bandpy, M.G., Ellahi, R., and Zeeshan, A., 2014, "Simulation of MHD CuO-Water Nanofluid Flow and Convective Heat Transfer Considering Lorentz Forces," Journal of Magnetism and Magnetic Materials, 369, 69-80.

http://dx.doi.org/10.1016/j.jmmm.2014.06.017

Sheikholeslami, M., Gorji-Bandpya, M., and Ganji, D.D., 2013, "Numerical Investigation of MHD Effects on $\mathrm{Al}_{2} \mathrm{O}_{3}$-Water Nanofluid Flow and Heat Transfer in a Semi-Annulus Enclosure Using LBM," Energy, 60, 501-510. http://dx.doi.org/10.1016/i.energy.2013.07.070

Sheikholeslami, M., Gorji-Bandpya, M., and Vajravelu, K., 2015, "Lattice Boltzmann Simulation of MHD Natural Convection Heat Transfer of $\mathrm{Al}_{2} \mathrm{O}_{3}-$ Water Nanofluid in a Horizontal Cylindrical 
Enclosure with an Inner Triangular Cylinder," International Journal Heat Mass Transfer, 80, 16-25.

http://dx.doi.org/10.1016/j.ijheatmasstransfer.2014.08.090

Soleimani, S., Sheikholeslami, M., Ganji, D.D., and Gorji-Bandpay, M., 2012, "Natural Convection Heat Transfer in a Nanofluid Filled SemiAnnulus Enclosure," International Communication in Heat and Mass Transfer, 39, 565-574.

http://dx.doi.org/10.1016/j.icheatmasstransfer.2012.01.016

Tiwari, R.K., and Das, M.D., 2007, "Heat Transfer Augmentation in a Two-Sided Lid-Driven Differentially Heated Square Cavity Utilizing Nanofluids," International Journal of Heat and Mass Transfer, 50 2002-2018.

http://dx.doi.org/10.1016/j.ijheatmasstransfer.2006.09.034

Trisaksri, V., and Wongwises, S., 2009, "Critical Review of Heat Transfer Characteristics of Nanofluids", Renewable and Sustainable Energy Reviews, 11, 512-523.

http://dx.doi.org/10.1016/j.rser.2005.01.010
Turkyilmazoglu, M., 2014, "Exact Analytical Solutions for Heat and Mass Transfer of MHD Slip Flow in Nanofluids. Chemical Engineering Science, 84, 182-187.

http://dx.doi.org/10.1016/j.ces.2012.08.029

Venkateswarlu, B., and Satya Narayana, P.V., 2015, "Chemical Reaction and Radiation Absorption Effects on the Flow and Heat Transfer of a Nanofluid in a Rotating System," Appl Nanosci, 5, 351360

http://dx.doi.org/10.1007/s13204-014-0324-3

Venkateswarlu, B., and Satya Narayana, P.V., 2015, "MHD ViscoElastic Fluid Flow over a Continuously Moving Vertical Surface with Chemical Reaction," Walailak J. sci. Eng., 12 (9), 775-783.

Xu, H., Fan, T., and Pop, I., 2013, "Analysis of Mixed Convection Flow of a Nanofluid in a Vertical Channel with the Buongiono Mathematical Model," International Communication in Heat and Mass Transfer, 44, 15-22.

http://dx.doi.org/10.1016/j.icheatmasstransfer.2013.03.015 